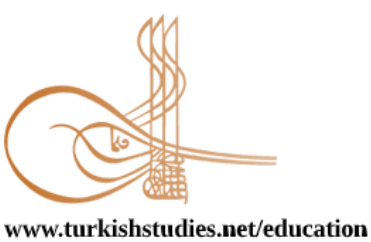

www.turkishstudies.net/education
Turkish Studies - Educational Sciences

eISSN: 2667-5609

Research Article / Araştırma Makalesi

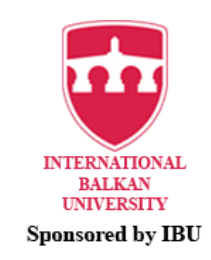

Sponsored by IBU

\title{
Boş Zaman Engelleri Farklılıkları: Kadın Üniversite Öğrencileri Örneği
}

The Diversity of Free Time Obstacles: The Example of Woman University Students

\author{
Meliha Uzun* - Osman İmamoğlu**
}

\begin{abstract}
The participation of free time activities, which have a positive impact on people's life both physical, social and psychological, is affected by various factors. It has been seen that the participation of free time activities is affected by many factors like free time motivation, free time facility, free time obstacles, the strategy of coping with free time obstacles and free time attitude (Lapa ve Köse, 2018). In this study, the differences of Leisure Barriers were investigated in the female students studying in the University who studied in different departments. Leisure barriers Scale were applied to 380 female students in total. One-way analysis of variance (ANOVA), LSD and t-test were used in statistical processes. According to the departments, there was a statistically significant difference in leisure scales, individual psychology, lack of knowledge, facility, lack of friends, time, lack of attention sub-dimensions and total scale score. This difference was caused by students who did not receive sports training. There was a difference between the individual psychology, lack of knowledge, facility, time and lack of attention scores of female students who do receive sports education and female students who do not receive sports education. There was no difference in terms of leisure disabilities between the students of the teaching department, the coaching department and the sports management department. It was concluded that getting sports education at university level affects leisure time barriers in university student women. Free time barriers did not differ among female students who stated that their health was good and very good. In a study involving students with poor or average health, it is recommended to investigate leisure disabilities.
\end{abstract}

Structured Abstract: Introduction: Free (free) time according to the definition of the World Free Time and Recreation Union; It is a special area of human life, with the benefits of choice, creativity, satisfaction and satisfaction and pioneering entertainment that increases personal satisfaction. The concept of activity mostly covers multiple forms of physical, in addition to intellectual, social, aesthetic and spiritual elements (Ağı̈önü, 2007). The woman students who do not take sport education have a bad score in individual psychology, lack of information, facilitiy, time and lack of interest than the students who take sport education. Significant differences were not founded among the students who take sport education and the work of trainers. The pursuit of life satisfaction and the cure for negative experiences impel People to have free time activities apart from the life necessities. Free time activities include relaxtion, entertainment, improving skills and participation in social life voluntarily after full filling one's professional and social duties (Solakumur and his friends 2019). The participation of free time activities, which have a positive impact on people's life both physical, social and

\footnotetext{
* Dr. Öğr. Üyesi, Şırnak Üniversitesi, Beden Eğitimi ve Spor Yüksekokulu, Antrenörlük Eğitimi Bölümü Asst. Prof. Dr., Sirnak University, High School of Physical Educaiton and Sport, Coaching Education Department ORCID 0000-0002-1691-3504 melihauzunn16@gmail.com

** Prof. Dr., Ondokuz Mayıs Üniversitesi, Spor Bilimleri Fakültesi, Spor Yöneticiliği Bölümü

Prof. Dr., Ondokuz Mayis University, Faculty of Sport Sciences, Department of Sport Management

ORCID 0000-0001-6671-6042

osmani55@ hotmail.com

Cite as/ Atıf: Uzun, M. \& İmamoğlu, O. (2020). Boş zaman engelleri farklılıkları: kadın üniversite öğrencileri örneği,

Turkish Studies-Education, 15(4), 3001-3012. https://dx.doi.org/10.47423/TurkishStudies.42869

Received/Geliş: 14 April/Nisan 2020

Accepted/Kabul: 25 August/Ağustos 2020

Copyright (C INTAC LTD, Turkey

Checked by plagiarism software

Published/Yayın: 30 August/Ağustos 2020

CC BY-NC 4.0
} 
psychological, is affected by various factors. It has been seen that the participation of free time activities is affected by many factors like free time motivation, free time facility, free time obstacles, the strategy of coping with free time obstacles and free time attitude (Lapa ve Köse, 2018). While the participation in free time activities varies according to the way of life, characteristics and time usage of the individuals, the type of activities, the ways of participation and the time that individuals devote to these activities; It is affected by many factors such as race, social and personal characteristics, age and gender (Tolukan, 2010). Higher education students spend their free time in the education process, which is outside the activities related to working and to continue their lives, with various activities. In university education, the recreation activities that the individual will participate in, other than vocational knowledge education, can see their life without distorting them, and they will realize themselves by engaging in their own skills and abilities (Arslan, 2013). For this reason, in this study it is purposed to search the differences of free time obstacles among the woman University students from different branches. This study was conducted with women University students from different faculties of Ondokuz Mayis University. This research group is consisted of 380 students from sport sciences 267, college of education, Faculty of arts and science and faculty of engineering 113. "ID form" and " free time obstacle scale" were used for collecting data. Free time obstacle scale-18 has been adapted to Turkish by Gürbüz and Karaküçük 2007 and the analysis of the confirmative factor has been done by Gürbüz and his friends 2012. The scale form used in this investigation is consisted of 18 items and 6 sub dimensions. These sub dimensions are (a) the psychology of individual 3 (b) lack of information 3 (c) facility 3 (d) lack of friends 3 (e) lack of time and interest 3.1 definitely junk 2 junk 3 significant 4 very significant options were presented and it was demanded to choose the most suitable options. For this study, the internal consistency coefficient of the scale was assigned as 0.82 .SPSS 23 programme was used to analyse data. While evaluating the data, compliance with normal distribution was searched by "the test of Kolmogorov smirnov" and it was detected that all the data adjust with compliance with normal distribution. One way analysis of variables (ANOVA) has been applied for statistical process, LSD and the t-test has been applied for detection of difference. The average of the woman's age is identified as 21.28 , length $169.10 \mathrm{~cm}$, weight 62.18 and body mass index $21.77 \mathrm{~kg} / \mathrm{m}^{2}$.According to the departments, there was a statistically significant difference in leisure scales, individual psychology, lack of knowledge, facility, lack of friends, time, lack of attention subdimensions and total scale score $(\mathrm{p}<0.001)$. This difference was caused by students who did not receive sports training. There was a difference between the individual psychology, lack of knowledge, facility, time and lack of attention scores of female students who do receive sports education and female students who do not receive sports education $(\mathrm{p}<0.001)$. In the investigation significant differences have been determined in free time scales of the psychology of individual, lack of information, facilitiy, lack of friends, time and lack of interest ( $p>0.05)$. It was concluded that getting sport education as a university student affects the free time obstacles. Free time obstacles did not differ among the students who indicated their medical condition as good and very good. It is recommended that free time obstacles be investigated among the students including bad and under good medical conditions.

Keywords: Recreation, Leisure Barriers, Woman Students, University, Free Time

Öz: İnsan yaşamını hem bedensel, psikolojik ve sosyal açıdan çok olumlu etkileyen serbest zaman aktivitelerine katılım birçok faktörten etkilenmektedir. Serbest zaman katılımını, motivasyon, kolaylaştırıcılar, engeller, engelleri ile baş etme stratejileri ve tutum gibi birçok faktörün etkilediği belirtilir (Lapa ve Köse, 2018). Bu sebeple çalışmada, üniversitede farklı bölümlerde öğrenim görmekte olan kadın öğrencilerin boş zaman engelleri arasındaki farklar araştırılmıştır. Toplam 380 kadın öğrenciye Boş Zaman Engelleri Ölçeği uygulanmıştır. İstatistiksel işlemlerde tek yönlü varyans analizi (ANOVA), LSD ve t- testi kullanılmıştır. Bölümlere göre boş zaman ölçekleri bireysel psikoloji, tesis, zaman, bilgi eksikliği, arkadaş ve ilgi eksikliği alt boyutlarında ve toplam ölçek puanında istatistiksel olarak anlamlı farklılık bulunmuştur. Bu farklılık spor eğitimi almayan öğrencilerden kaynaklanmıştır. Spor eğitimi almayan kadın öğrencilerin spor eğitimi alan kadın öğrencilerden bireysel psikoloji, bilgi eksikliği, tesis, zaman ve ilgi eksikliği puanları daha kötü bulunmuştur. Öğretmenlik bölümü, antrenörlük bölümü ve spor yöneticiliği bölümü öğrencileri arasında boş zaman engelleri açısından farklılık bulunmamıştır. Üniversite düzeyinde spor eğitimi almanın, üniversite öğrencisi kadınlarda boş zaman engellerini etkilediği sonucuna varılmıştır. Sağlık durumunu iyi ve çok iyi olarak belirten kadın öğrencilerde boş zaman engelleri farklılık göstermemiştir. Sağlık durumu kötü veya iyi altında olan öğrencileri de kapsayan bir çalışmada boş zaman engellerinin araştırılması önerilir. 
Anahtar Kelimeler: Rekreasyon, Boş Zaman Engelleri, Kadın Öğrenciler, Üniversite, Serbest Zaman

\section{Giriş}

Zaman, hayatta en değerli kavramdır ve onu niteliksiz şekilde geçirmek, yaşamın boşa geçirilmesi anlamını taşımaktadır (Baltaş ve Baltaş, 2012). Zamanını etkin ve verimli bir şekilde kullanan bir birey ne yapacağını iyi bilir ve onu en yararlı şekilde nasıl kullanabileceği hakkında bilgi sahibidir. Böylelikle hedeflerine göre vaktini ayarlar (Alay ve Koçak, 2003). Dünya Serbest (Boş) Zaman ve Rekreasyon Birliği'ne göre serbest zaman; bireylere seçme şansı tanır, onların yaratıcılıklarını geliştirir, yararları ile birlikte bireylere hoşnutluk verir ve kişisel haz almalarını sağlar. Bu bakımdan bireylerin hayatında özel bir alan olarak görülmektedir. Aktivite kavramı genel olarak fiziksel olarak düşünülmektedir. Ek olarak entelektüel ve sosyal öğelerin yanı sıra ruhsal ve estetik yönden de birçok formu içinde barındırmaktadır (A ğılönü, 2007). Egzersiz ve fiziksel aktivite, daha iyi fiziksel ve zihinsel sağlığa ulaşmaya, yaşam kalitesini artırmaya yardımcı olur (Atan vd., 2012). Serbest zaman etkinlikleri; bireylerin zorunlu işleri dışında kalan, bir amaç çerçevesinde yapılan, kişisel haz sağlayan, gönüllülüğe dayalı olan, başkasına devredilme gibi şansı olmayan, kişiye canlılık kazandıran ve mutluluk veren, hem aktif hem de pasif olarak yapılabilen her türlü fiziksel, sosyal, zihinsel ve ruhsal aktiviteler olarak tanımlanmaktadır (Güngörmüş vd., 2006). Toplumlarda farklı yeteneklere sahip tüm insanların kişisel, bedensel ve sosyal kapasitelerini olumlu olarak artırabilmeleri amacı ile rekreasyonel etkinliklere katılmaları gerekir (Aksoy, 2020). İnsanların yaşadıkları olumsuzluklara çare aramaları ve yaşamdan doyum sağlama arayışları, onları yaşam gereksinimlerinin elde edilmesi için yapılan durumların haricinde kalan serbest zaman dilimlerinde bir takım aktivitelere yönlendirmiştir. Serbest zaman etkinlikleri, bireyin mesleklerine ve topluma yönelik görevlerini yaptıktan sonra kendi isteğiyle girişebileceği birçok faaliyeti kapsar. Bunlar; dinlenmek, bilgi ve becerilerini geliştirmek, eğlenmek, toplum yaşamına gönüllü bir şekilde katılmak gibi faaliyetlerdir (Ermiş vd., 2018; Solakumur vd., 2019). Serbest zaman etkinlikleri gerek fiziksel gerekse psikolojik ve sosyal yönden bireyleri olumlu yönde etkiler. Fakat bu etkinliklere katılımı etkileyen birçok faktör bulunmaktadır. Serbest zaman; motivasyonu, kolaylaştırıcıları, engelleri, engeller ile baş etme stratejileri ve tutumu gibi birçok faktör serbest zaman katılımını etkilemektedir (Lapa ve Köse, 2018). İlaveten, kişilerin yaşam tarzı ve zamanı kullanma durumlarına göre de değişiklik gösterebilir. Ayrıca, aktivitelerin türü, katılım biçimleri ve kişilerin bu aktivitelere ayırdıkları zamanda bu etmenler arasında belirtilebilir. Yine, toplumsal özellikler, 1rk, bireysel farkl1l1klar, yaş ve cinsiyet gibi maddelerde bu etmenler kapsamında değerlendirilebilir (Tolukan, 2010). Maddi imkanların olmaması ve zamanın yetersizliği günümüzde en çok şikayet edilen unsurlar olarak görülmektedir (Akatay, 2008; Gülbahçe, 1996). Ancak kıyaslandığında, paranın tedarik edilebildiği fakat zamanın telafisinin mümkün olmadığı görülmektedir (Dinç vd., 2019).

Öğrencilerin ders dışında bazı uğraş gösterdikleri etkinlikler vardır. Bu etkinlikler onların eğitim hayatlarında başarılı olmalarına katkı sağlamaktadır. Bunlar; spor, müzik, güzel sanatlar, folklor gibi dallardır (Lakot, 2015). Etkinlikler, üniversite öğrencilerinin yeteneklerine uygun uğraşlar edinmelerini sağlar ve bu yetenekler doğrultusunda kendilerini keşfetmelerine olanak tanır. Ayrıca, kendi yaşantılarını çarpıtmadan görebilmelerine imkan sağlar (Arslan, 2013). Serbest zaman engellerine yönelik çalışmalar incelendiğinde daha çok kadınlar ve fiziksel aktivite engellerine odaklanıldığı görülmektedir. Engeller ile baş etme stratejilerine ilişkin araştırmaların ise açık alanlarda rekreasyon, engelli bireyler, kadınlar ve bunların içinde değişik dinden olan ve farklı cinsel eğilimi olan kadınlara odaklanıldığı görülmektedir (Lapa ve Köse, 2018). Serbest zamanın değerlendirilmesi, insanın içinde bulunduğu her zaman dikkate alınması gereken bir durum olmuştur (Köse ve Yılmaz, 2016). Boş zamanı doğru ve verimli bir şekilde değerlendirmek gereklidir (Kırtepe ve Uğurlu, 2018). Genç bireylerin serbest zamanlarını yaşam kalitesini arttıracak şekilde etkili ve verimli bir şekilde değerlendirmesi oldukça önemlidir. Bu bağlamda etkinliklere katılımı engelleyen unsurların belirlenmesi oldukça önem arz etmektedir. Bu sebeple bu çalışmada, üniversitede değişik 
bölümlerde eğitim ve öğretim almakta olan kadın öğrencilerin boş zaman engelleri arasındaki farkların araştırılması amaçlanmıştır. Kadının toplumsal hayatta bazı görev ve sorumluluklara sahip olduğunu söylemek mümkündür. Bu bağlamda kadın, zamanının çoğunu görev ve sorumluluklarına harcayacak ve bu ödevlerini yerine getirdikten sonra kendine vakit ayırabilecektir. Bu da kadın açısından bir engel olarak nitelendirilebilir. İlaveten, kadının erkeğe göre daha çekingen olması ve pasif kalması da etkinliklere katılmasında engelleyici unsur olarak düşünülebilir. Araştırmada özellikle kadınlara yönelik çalışılmasında bu tür düşüncelerin tetiklemesinin etkisi olduğu söylenebilir.

\section{Yöntem}

\section{Çalışma Grubu}

$\mathrm{Bu}$ araştırma, Ondokuz Mayıs Üniversitesinin bazı fakültelerinde öğrenim görmekte olan kadın öğrencileri kapsamaktadır. Çalışma grubundaki öğrenciler; Spor Bilimlerinden (Beden Eğitimi ve Spor Öğretmenliği; Antrenörlük Eğitimi; Spor Yöneticiliği) 267 öğrenci ve diğer bölümlerden (Eğitim Fakültesi; Fen Edebiyat Fakültesi; Mühendislik Fakültesi) 113 öğrenci olmak üzere toplam 380 kişiden oluşmaktadır.

\section{Veri Toplama Araçları}

Verilerin elde edilmesinde araştırmacıların hazırlamış olduğu "Kişisel Bilgi Formu" ile Türkçeye uyarlanan "Boş Zaman Engelleri Ölçeği-18” kullanılmıştır.

\section{Boş Zaman Engelleri Ölçeği}

“Boş Zaman Engelleri Ölçeği-18”Alexandris ve Carroll (1997) tarafindan geliştirilmiş olup, Gürbüz ve Karaküçük (2007) tarafindan Türkçeye uyarlanmış ve Gürbüz ve arkadaşları (2012) tarafından doğrulayıcı faktör analizi yapılmıştır. Ölçek formu 18 maddeden oluşmaktadır ve 6 alt boyuttur. Bunlar; (a) Birey Psikolojisi, (b) Bilgi Eksikliği, (c) Tesis, (d) Arkadaş Eksikliği, (e) Zaman ve (f) İlgi Eksikliği şeklindedir. Her alt boyut 3 maddeden oluşmuştur. Her bir soru için 1: "Kesinlikle Önemsiz", 2: "Önemsiz”, 3: “Önemli”, 4: “Çok Önemli”, seçenekleri öğrencilere yöneltilmişolup kendileri için en uygun seçeneği tercih etmeleri istenmiştir. Bu çalışma için ölçeğin iç tutarlılık katsayısı 0,82 olarak bulunmuştur.

\section{Verilerin Değerlendirilmesi}

Araştırma verilerinin değerlendirilmesi bilgisayar ortamında SPSS 23.0 paket programında yapılmıştır. Veriler değerlendirilirken "Kolmogorov Smirnov Testi" ile normal dağılıma uygunluğu araştırılmış ve tüm verilerin normal dağılıma uyduğu tespit edilmiştir. İstatistiksel işlemlerde tek yönlü varyans analizi, farklılığın tespiti için LSD ve t- testi uygulanmıştır.

\section{Bulgular}

Tablo 1:Kadın Öğrencilerin Antropometrik Özellikleri

\begin{tabular}{lcc}
\hline $\mathbf{n}=\mathbf{3 8 0}$ & $\overline{\mathbf{X}}$ & $\mathbf{S S}$ \\
\hline Yaş (Yıl) & 21,28 & 1,72 \\
\hline Boy Uzunluğu (cm) & 169,10 & 10,06 \\
\hline Vücut Ă̆ırlı̆̆ $(\mathbf{k g})$ & 62,18 & 7,94 \\
\hline Beden Kütle İndeks $\left(\mathbf{k g} / \mathbf{m}^{2}\right)$ & 21,77 & 2,14 \\
\hline
\end{tabular}

Öğrencilerin ortalama yaşı, boy uzunluğu, vücut ağırlı̆̆ı, beden kütle indeksi değerleri sırasıyla: $21,28 \pm 1,72 ; 169,10 \pm 10,06 \mathrm{~cm} ; 62,18 \pm 7,94 \mathrm{~kg} ; 21,77 \pm 2,14 \mathrm{~kg} / \mathrm{m}^{2}$ olarak bulunmuştur (Tablo 1). 
Tablo 2: Boş Zaman Engelleri Ölçeği Puanlarının Yaş Değiş̧kenine Göre T-Testi Sonuçları

\begin{tabular}{|c|c|c|c|c|c|c|}
\hline $\mathrm{n}=\mathbf{3 8 0}$ & Yaş kategori & $\mathbf{N}$ & $\overline{\mathbf{X}}$ & SS & t testi & p \\
\hline \multirow{2}{*}{ Bireysel psikoloji } & 20 yaş ve altı & 182 & 9,59 & 1,92 & 0,66 & 0,365 \\
\hline & 21 yaş ve üstü & 198 & 9,56 & 2,10 & & \\
\hline \multirow[t]{2}{*}{ Bilgi eksikliği } & 20 yaş ve altı & 182 & 9,61 & 2,15 & 0,58 & 0,210 \\
\hline & 21 yaş ve üstü & 198 & 9,75 & 2,32 & & \\
\hline \multirow[t]{2}{*}{ Tesis } & 20 yaş ve altı & 182 & 10,07 & 2,15 & $-0,63$ & 0,260 \\
\hline & 21 yaş ve üstü & 198 & 10,11 & 2,93 & & \\
\hline \multirow[t]{2}{*}{ Arkadaş eksikliği } & 20 yaş ve altı & 182 & 8,53 & 2,30 & 2,12 & $2,15^{*}$ \\
\hline & 21 yaş ve üstü & 198 & 7,89 & 2,25 & & \\
\hline \multirow[t]{2}{*}{ Zaman } & 20 yaş ve altı & 182 & 9,03 & 2,11 & $-2,55$ & $2,43^{*}$ \\
\hline & 21 yaş ve üstü & 198 & 10,01 & 2,12 & & \\
\hline \multirow[t]{2}{*}{ İlgi eksikliği } & 20 yaş ve altı & 182 & 8,43 & 2,13 & 0,46 & 0,020 \\
\hline & 21 yaş ve üstü & 198 & 8,36 & 2,11 & & \\
\hline \multirow[t]{2}{*}{ Toplam puan } & 20 yaş ve altı & 182 & 55,26 & 7,78 & 0,98 & 0,310 \\
\hline & 21 yaş ve üstü & 198 & 55,68 & 7,82 & & \\
\hline
\end{tabular}

*p<0,05

Öğrencilerin yaş kategorisine göre boş zaman engel durumları incelendiğinde arkadaş eksikliği ve zaman boyutlarında anlamlı farklılık olduğu görülmektedir $(\mathrm{p}<0,05)$.

Tablo 3: Öğrencilerin Bölümlerine Göre ANOVA-LSD Testi Sonuçları

\begin{tabular}{|c|c|c|c|c|c|c|}
\hline$n=380$ & Bölüm & $\mathbf{N}$ & $\overline{\mathbf{X}}$ & SS & F/LSD & $\mathbf{p}$ \\
\hline \multirow{4}{*}{$\begin{array}{l}\text { Bireysel } \\
\text { Psikoloji }\end{array}$} & Beden Eğitimi Öğretmenliği (1) & 85 & 10,24 & 1,24 & \multirow{4}{*}{$\begin{array}{l}36,96^{* *} \\
4<1,2,3\end{array}$} & \multirow{4}{*}{0,001} \\
\hline & Antrenörlük (2) & 98 & 9,77 & 0,79 & & \\
\hline & Spor Yöneticiliği(3) & 84 & 10,01 & 1,40 & & \\
\hline & Diğer (4) & 113 & 8,31 & 1,68 & & \\
\hline \multirow{4}{*}{$\begin{array}{l}\text { Bilgi } \\
\text { Eksikliği }\end{array}$} & Beden Eğitimi Öğretmenliği (1) & 85 & 10,34 & 0,86 & \multirow{4}{*}{$\begin{array}{l}38,11 \text { ** } \\
4<1,2,3\end{array}$} & \multirow{4}{*}{0,001} \\
\hline & Antrenörlük (2) & 98 & 9,87 & 0,84 & & \\
\hline & Spor Yöneticiliği (3) & 84 & 10,33 & 1,44 & & \\
\hline & Diğer (4) & 113 & 8,18 & 2,15 & & \\
\hline \multirow{4}{*}{ Tesis } & Beden Eğitimi Öğretmenliği (1) & 85 & 10,24 & 1,34 & \multirow{4}{*}{$\begin{array}{l}18,45^{* *} \\
4<1,2,3\end{array}$} & \multirow{4}{*}{0,001} \\
\hline & Antrenörlük (2) & 98 & 10,41 & 1,20 & & \\
\hline & Spor Yöneticiliği (3) & 84 & 10,60 & 1,05 & & \\
\hline & Diğer (4) & 113 & 9,11 & 1,96 & & \\
\hline \multirow{4}{*}{$\begin{array}{l}\text { Arkadaş } \\
\text { Eksikliği }\end{array}$} & Beden Eğitimi Öğretmenliği (1) & 85 & 8,21 & 2,33 & \multirow{4}{*}{$\begin{array}{l}9,23 * * \\
4<1,2,3\end{array}$} & \multirow{4}{*}{0,001} \\
\hline & Antrenörlük (2) & 98 & 8,71 & 2,10 & & \\
\hline & Spor Yöneticiliği (3) & 84 & 8,35 & 1,96 & & \\
\hline & Diğer (4) & 113 & 7,57 & 2,29 & & \\
\hline \multirow{4}{*}{ Zaman } & Beden Eğitimi Öğretmenliği (1) & 85 & 10,09 & 1,16 & \multirow{4}{*}{$\begin{array}{l}25,62 * * \\
4<1,2,3\end{array}$} & \multirow[t]{4}{*}{0,001} \\
\hline & Antrenörlük (2) & 98 & 9,81 & 1,81 & & \\
\hline & Yöneticilik (3) & 84 & 9,77 & 1,54 & & \\
\hline & Diğer (4) & 113 & 8,40 & 1,63 & & \\
\hline \multirow{4}{*}{$\begin{array}{l}\text { İlgi } \\
\text { Eksikliği }\end{array}$} & Beden Eğitimi Öğretmenliği (1) & 85 & 9,02 & 1,64 & \multirow{4}{*}{$\begin{array}{l}11,34 * * \\
4<1,2,3\end{array}$} & \multirow{4}{*}{0,001} \\
\hline & Antrenörlük (2) & 98 & 8,30 & 2,42 & & \\
\hline & Yöneticilik (3) & 84 & 8,85 & 2,02 & & \\
\hline & Diğer (4) & 113 & 7,42 & 2,32 & & \\
\hline \multirow[b]{4}{*}{$\begin{array}{l}\text { Toplam } \\
\text { puan }\end{array}$} & Beden Eğitimi Öğretmenliği (1) & 85 & 56,84 & 4,78 & \multirow{4}{*}{$\begin{array}{l}55,62 * * \\
4<1,2,3\end{array}$} & \multirow{4}{*}{0,001} \\
\hline & Antrenörlük (2) & 98 & 55,57 & 5,40 & & \\
\hline & Yöneticilik (3) & 84 & 55,62 & 6,43 & & \\
\hline & Diğer (4) & 113 & 47,85 & 6,28 & & \\
\hline
\end{tabular}


Öğrencilerin bölümlerine göre boş zaman engel durumları incelendiğinde; tüm alt boyutlar ve toplam puanda anlamlı farklılık olduğu görülmektedir $(p<0,001)$. LSD testi sonuçlarına göre; boş zaman engelleri ölçeği bireysel psikoloji, bilgi eksikliği, tesis, arkadaş eksikliği, zaman, ilgi eksikliği alt boyutlarında ve toplam puanda diğer bölümlerde okuyan (eğitim fakültesi; fen edebiyat fakültesi; mühendislik fakültesi) öğrencilerin ortalamaları, beden eğitimi öğretmenliği, antrenörlük ve yöneticilik bölümlerinde okuyan öğrencilerin ortalamalarından anlamlı şekilde düşük bulunmuştur (Tablo 3).

Tablo 4: Öğrencilerin Kendini Sağlıklı Olarak Kabul Görme Durumuna Göre T Testi Sonuçları

\begin{tabular}{|c|c|c|c|c|c|c|}
\hline $\mathrm{n}=\mathbf{3 8 0}$ & Sağlık durumu & $\mathbf{N}$ & $\overline{\mathbf{X}}$ & SS & t testi & $\mathbf{p}$ \\
\hline \multirow[t]{2}{*}{ Bireysel Psikoloji } & İyi & 294 & 9,10 & 1,59 & 0,66 & \\
\hline & Çok iyi & 86 & 8,95 & 2,21 & & 0,560 \\
\hline \multirow[t]{2}{*}{ Bilgi eksikliği } & İyi & 294 & 9,04 & 1,96 & $-1,18$ & \\
\hline & Çok iyi & 86 & 9,41 & 2,12 & & 0,720 \\
\hline \multirow[t]{2}{*}{ Tesis } & İyi & 294 & 9,67 & 1,73 & $-0,27$ & 0,560 \\
\hline & Çok iyi & 86 & 9,73 & 1,93 & & \\
\hline \multirow[t]{2}{*}{ Arkadaş eksikliği } & İyi & 294 & 7,86 & 2,18 & 1,90 & \\
\hline & Çok iyi & 86 & 7,18 & 2,87 & & 0,310 \\
\hline \multirow[t]{2}{*}{ Zaman } & İyi & 294 & 9,12 & 1,70 & 1,66 & \\
\hline & Çok iyi & 86 & 8,69 & 1,88 & & 0,354 \\
\hline \multirow[t]{2}{*}{ İlgi eksikliği } & İyi & 294 & 8,08 & 2,30 & 1,881 & \\
\hline & Çok iyi & 86 & 7,42 & 2,10 & & 0,359 \\
\hline \multirow[t]{2}{*}{ Toplam puan } & İyi & 294 & 51,98 & 7,01 & 1,43 & 0,387 \\
\hline & Çok iyi & 86 & 50,46 & 8,64 & & \\
\hline
\end{tabular}

$\mathbf{p > 0 , 0 5}$

Tablo 4'te öğrencilerin kendini sağlıklı olarak kabul görme durumlarına göre; boş zaman engelleri ölçeği bireysel psikoloji, bilgi eksikliği, tesis, arkadaş eksikliği, zaman, ilgi eksikliği alt boyutlarında ve toplam puanda istatistiksel olarak anlamlı bir farkl1lı yoktur ( $\mathrm{p}>0.05$ ), (Tablo 3 ). 


\begin{tabular}{|c|c|c|c|c|c|c|}
\hline$n=380$ & $\begin{array}{l}\text { Gelir } \\
\text { Durumu }\end{array}$ & $\mathbf{N}$ & $\overline{\mathbf{X}}$ & SS & $\mathbf{F}$ & $\mathbf{p}$ \\
\hline \multirow{4}{*}{$\begin{array}{l}\text { Bireysel } \\
\text { psikoloji }\end{array}$} & $500 \mathrm{tl}$ ve alt 1 & 130 & 9,69 & 2,53 & \multirow[t]{4}{*}{0,83} & \multirow[t]{4}{*}{0,398} \\
\hline & $501-1000 \mathrm{tl}$ & 134 & 9,7 & 2,45 & & \\
\hline & $1001-1500 \mathrm{tl}$ & 75 & 9,54 & 2,24 & & \\
\hline & $1501 \mathrm{tl}$ ve üstü & 41 & 9,39 & 2,25 & & \\
\hline \multirow[t]{4}{*}{ Bilgi eksikliği } & 500 tl ve alt & 130 & 9,54 & 2,73 & \multirow[t]{4}{*}{0,54} & \multirow[t]{4}{*}{0,540} \\
\hline & $501-1000 \mathrm{tl}$ & 134 & 9,75 & 2,63 & & \\
\hline & $1001-1500 \mathrm{tl}$ & 75 & 9,65 & 2,54 & & \\
\hline & $1501 \mathrm{tl}$ ve üstü & 41 & 9,77 & 2,55 & & \\
\hline \multirow[t]{4}{*}{ Tesis } & 500 tl ve alt & 130 & 10,11 & 2,67 & \multirow[t]{4}{*}{0,43} & \multirow[t]{4}{*}{0,610} \\
\hline & $501-1000 \mathrm{tl}$ & 134 & 9,97 & 2,29 & & \\
\hline & $1001-1500 \mathrm{tl}$ & 75 & 10,07 & 2,25 & & \\
\hline & $1501 \mathrm{tl}$ ve üstü & 41 & 10,22 & 2,23 & & \\
\hline \multirow{4}{*}{$\begin{array}{l}\text { Arkadaş } \\
\text { eksikliği }\end{array}$} & 500 tl ve altı & 130 & 8,21 & 2,31 & \multirow[t]{4}{*}{098} & \multirow[t]{4}{*}{0,321} \\
\hline & $501-1000 \mathrm{tl}$ & 134 & 8,17 & 2,24 & & \\
\hline & $1001-1500 \mathrm{tl}$ & 75 & 8,24 & 2,42 & & \\
\hline & $1501 \mathrm{tl}$ ve üstü & 41 & 8,23 & 2,21 & & \\
\hline \multirow[t]{4}{*}{ Zaman } & 500 tl ve alt1 & 130 & 9,45 & 2,93 & \multirow[t]{4}{*}{0,37} & \multirow[t]{4}{*}{0,385} \\
\hline & $501-1000 \mathrm{tl}$ & 134 & 9,98 & 2,22 & & \\
\hline & $1001-1500 \mathrm{tl}$ & 75 & 9,26 & 2,73 & & \\
\hline & $1501 \mathrm{tl}$ ve üstü & 41 & 9,38 & 2,83 & & \\
\hline \multirow[t]{4}{*}{ İlgi eksikliği } & 500 tl ve altı & 130 & 8,39 & 2,19 & \multirow[t]{4}{*}{0,38} & \multirow[t]{4}{*}{0,385} \\
\hline & $501-1000 \mathrm{tl}$ & 134 & 8,41 & 2,37 & & \\
\hline & $1001-1500 \mathrm{tl}$ & 75 & 8,43 & 2,77 & & \\
\hline & $1501 \mathrm{tl}$ ve üstü & 41 & 8,36 & 2,78 & & \\
\hline
\end{tabular}

p>0,05

Gelir düzeyine göre Boş Zaman Engelleri Ölçeği boyutlarında istatistiksel olarak önemli bir farklı1ık bulunmamıştır $(\mathrm{p}>0,05)$.

\section{Tartışma ve Sonuç}

Araştırmaya katılan kadınların yaş ortalaması 21,28 yıl; boy uzunlukları $169,10 \mathrm{~cm}$; vücut ağırlıkları $62,18 \mathrm{~kg}$ ve Beden kütle indeks değerleri $21,77 \mathrm{~kg} / \mathrm{m}^{2}$ olarak bulunmuştur (Tablo 1). Genel olarak, vücut kütle indeksi $25 \mathrm{~kg} / \mathrm{m}^{2}$ ve altında ise herkes sağlıklı olarak kabul edilir (Turgut vd., 2018). Bu çalışmadaki öğrenciler vücut ağırlığına göre formdadırlar.

Spor bilimlerinde okuyan kadın öğrencilerin boş zaman engelleri farklılıklarını belirlemek amacıyla yapılan bu çalışmada ölçekten elde edilen puan ortalamaları incelendiğinde; en yüksek ortalama tesis alt boyutunda $(\overline{\mathrm{X}}=10,60)$ görülürken; en düşük ortalama arkadaş eksikliği boyutunda $(\bar{X}=7,18)$ görülmüştür. Öztürk ve Bayazıt $(2020)$ halk eğitim merkezinde çalışan eğitmenler üzerinde yaptıkları çalışmada, en yüksek puan ortalamasını tesis alt boyutunda, en düşük puan ortalamasını ise arkadaş eksikliği alt boyutunda tespit etmişlerdir. Benzer şekilde, Batur (2019) tarafından yapılan araştırmada da, en yüksek değer ortalaması tesis boyutunda; en düşük değer ortalama ise arkadaş eksikliği boyutundadır. Çalışmamızın bulguları bu çalışmanın bulguları ile örtüşsmektedir.

Güler (2017) boş zaman engelleri ölçeği puanlarının yaş değişkenine göre farklılaşmadığını bulmuştur. Lakot (2015) ise yaşlara göre anlamlı bir şekilde farklılaştığını belirtmiştir. Demirtaş ve İmamoğlu (2018) çalışmalarında yaşlara göre zaman eksikliği ve arkadaş eksikliği alt boyutlarında anlamlı farklılık bulmuşlardır. Ekinci ve arkadaşları (2014) ise katılımcıların boş zaman engellerinin yaşlarına göre "zaman" alt boyutunda anlamlı olduğunu tespit etmişlerdir. Uzun ve arkadaşları (2017) çalışmalarında, lise öğrencilerinde yaş grubuna göre bireysel psikoloji ve tesis alt boyutlarında anlamlı bir farklılık belirlemişlerdir. Başka bir çalışmada fitness merkezlerinde spor 
yapan üniversite öğrencilerinin boş zaman stratejileri yaş kategorisi ve gelir durumuna göre farklılık gösterdiği belirtilmiştir (Aslan ve İmamoğlu, 2020). Bu çalışmada zaman eksikliği ve arkadaş eksikliği alt boyutlarında yaşlara göre anlamlı farkl1lık bulunmuştur $(\mathrm{p}<0,05)$. Alt boyutlarda bu farklılığın oluşmasında, katılımcıların özelliklerinin ve durumlarının etken olduğu söylenebilir.

Öğrencilerin yaşamın her alanında başarı olmalarında sosyal, kültürel, fiziksel, sanatsal ve oyun gibi birçok etkinliğin katkısı oldukça büyük öneme sahiptir (Karaküçük, 2008). Yalçın ve Ayhan (2020) kadınlar üzerinde yapmış oldukları araştırmada, rekreatif etkinliklere katılım fiziksel görünüş mükemmeliyetçiliğinin yanı sıra psikolojik anlamda da onların iyi olmalarına katk1 sağlamıştır. Ayrıca, bu etkinlikler onların iç ve dış güvenleri üstünde de oldukça önem arz etmektedir. Bir diğer araştırmada, etkinlik yapılan ve yapılmayan dönemler arasındaki duygu durumları incelenmiştir. Etkinlik yapılan dönemde bireylerin pozitif yönden (heyecanl, ilhaml, dikkatli, güçlü vs.) gelişmeler yaşadığ 1 gözlenmiştir (Eryılmaz ve Unur, 2019). Turan, Gülşen ve Bilaloğlu (2019) tarafindan yapılan bir diğer araştırmada da, boş zaman engelleri ile yaşam doyumu arasında ilişki olduğu saptanmıştır. Bu ilişki negatif yönlü olarak belirtilmiştir. Duygu inançları, insanların hangi duyguları yaşayabilecekleri, değiştirebilecekleri veya düzenleyecekleri hakkındaki değerlendirmelerini ifade eder (Goodman vd., 2020). Güler (2017) yapmış olduğu araştırmada, Spor Bilimlerinde okuyan öğrenciler ile diğer fakültelerde öğrenim gören öğrencilerin boş zamanlarını değerlendirmeleri arasında farklılık tespit etmiştir. Demirtaş ve İmamoğlu (2018) çalışmalarında fakülteye göre boş zaman engellerini incelemişlerdir. Buna göre; bilgi eksikliği, tesis alt boyutlarında ve toplam puanda farklılık bulmuşlardır. Emir (2012) araştırmasında alt boyutlardan en yüksek puanı tesis ve zamanda, en düşük puanı ise ilgi eksikliğinde olduğunu belirtmiştir. Tolukan (2010) ise araştırmasında en yüksek puanı bilgi eksikliğinde saptamıştır. Demirel ve Harmandar (2009) çalışmasında; "İlgi Eksikliği” faktörünün rekreatif aktivitelere katılımda engel olarak ilk sırada bulunduğunu izah etmiştir. Uzun ve arkadaşları (2017)'nın araştırmasında en düşük puan ilgi eksikliğidir. Solakumur ve arkadaşları (2019) tarafından yapılan çalışmada bölüme göre, rekreasyon bölümünün lehine tesis/hizmet, zaman ve ölçek toplam puanlarında anlamlı bir farklılık saptanmıştır. $\mathrm{Bu}$ çalışmada bölümlere göre boş zaman ölçekleri bireysel psikoloji, tesis, zaman, bilgi eksikliği, arkadaş eksikliği, ilgi eksikliği alt boyutlarında ve toplam ölçek puanında istatistiksel olarak anlamlı farkl1lık bulunmuştur ( $p<0,001$ ). Boş zaman engelleri ölçeği bireysel psikoloji, bilgi eksikliği, tesis, arkadaş eksikliği, zaman, ilgi eksikliği alt boyutlarında ve toplam puanda diğer bölümlerde okuyan (eğitim fakültesi; fen edebiyat fakültesi; mühendislik fakültesi) öğrencilerin ortalamaları, beden eğitimi öğretmenliği, antrenörlük ve yöneticilik bölümlerinde okuyan öğrencilerin ortalamalarından anlamlı şekilde düşük bulunmuştur. Spor eğitimi almayan kadın öğrencilerin spor eğitimi alan kadın öğrencilere göre bireysel psikoloji, bilgi eksikliği, tesis, zaman ve ilgi eksikliği puanları daha kötü bulunmuştur $(p<0,001)$. Spor eğitimi alan öğretmenlik, antrenörlük ve spor yöneticiliği bölüm öğrencilerinde boş zaman engelleri açısından farklılık bulunmamıştır ( $p>0,05)$. Karadeniz ve arkadaşları (2019)'nın yapmış oldukları bir araştırmada, spor bilimlerinde eğitim gören öğrencilerin serbest zaman değerlendirme tutumlarının daha olumlu düzeyde olduğu tespit edilmiştir. Yine, Akyüz ve Türkmen (2016) yapmış oldukları araştırmada sporla ilgili bölümlerde öğrenim gören öğrencilerin serbest zaman tutumlarının diğer bölümlerde öğrenim gören öğrencilerden daha olumlu olduğunu belirtmişlerdir. Çimen ve Sarol (2015) tarafından yapılan bir diğer araştırmada da benzer sonuçlar ortaya konulmuştur. Spor eğitimi almanın üniversite öğrencisi kadınlarda boş zaman engellerini etkilediği sonucuna varılmıştır.

Ermiş ve arkadaşları (2019) tarafından yapılan bir çalışmada bireysel psikoloji alt ölçeğinde sağlık eğitimi alan öğrencilerin ve tesis ve zaman alt ölçeğinde ise spor eğitimi alanların daha iyi olduğu bulunmuştur. Arkadaş eksikliği konusunda problem yaşayan bireyler bu durumu serbest zaman etkinliklerine katılmada bir kısıtlılık olarak görmektedir. Bu bireyler etkinliklere katılmak için arkadaş bulamamanın yanı sıra mevcut arkadaşlarıyla da farklı ilgi alanlarına sahip olduklarını belirtmektedirler. Arkadaş eksikliği konusuyla karşı karşıya kalan bireylerin kendileriyle aynı ilgi 
alanlarına sahip olan arkadaşları ile bir araya gelmeye çalıştıkları izah edilmiştir. Ayrıca, hemcinslerini tercih ettikleri ve böylece bu engellerin üstesinden gelmeye çalıştıkları belirtilmiştir (Hubbard ve Mannel, 2001). Bireylerin etkinliklere katılması için engel oluşturan etmenler arttıkça, engellerin aşılması için bireylerin bazı stratejilerini arttırmaları gerekmektedir (Lapa ve Köse, 2018). Bu çalışmada diğer kategorisinde olan öğrencilerin spor eğitimi alan kadın öğrencilere göre daha fazla arkadaş eksikliği, tesis konusunda daha az bilgileri olması, ilgi eksikliği yaşadığını söyleyebiliriz.

Rekreasyon (boş zaman etkinlikleri) insanların sosyal yaşamlarını canlandırmak, fiziksel ve zihinsel sağlıklarını korumalarına yardımcı olmak ve hayat kalitesini arttırmak amaçlı oluşan alanlardan biridir (Tordkilsen, 2005). Serbest zamanlarda gerçekleştirilen fiziksel aktiviteler bireylerin yaşamında oldukça büyük öneme sahiptir (Öztürk, 2019). Serbest zamanın etkili ve kaliteli bir biçimde kullanılmasına paralel olarak gençler kendini gerçekleştirme olanağı bulacak ve ruhen daha sağlıklı olacaklardır (Balcı vd., 2003). Herhangi bir rekreasyon aktivitesine katılmayan öğrencilerin boş zamanlarını değerlendirmede bir rekreasyon aktivitesine katılanlardan daha az zorluk yaşadıkları belirtilir. Başka bir deyişle, spor yapmayan öğrenciler, spor yapan öğrencilerin karşılaştığ 1 engellerle karşılaşmazlar (Aksoy ve Arslan, 2019). Bu çalışmada kendini sağlıklı olarak iyi ve çok iyi değerlendiren kadın öğrencilerin boş zaman engelleri ölçeği alt boyutlarında ve toplam ölçek puanlarında istatistiksel olarak anlamlı bir farklılık bulunmamıştır ( $\mathrm{p}>0,05)$. Bu kategoride sağlık durumunu kötü olarak nitelendirenler olmadığı için sağlık durumunun boş zaman engellerini nasıl etkilediği konusunda bu çalışmaya göre görüş belirtilememiştir. Çalışmada spor eğitimi alan bölümler ile spor eğitimi almayan öğrenciler arasındaki farklılıklar, rekreatif etkinliklere katılım şartlarının farklılı̆̆ına ilaveten hayat şartlarının farklılığı ve spor eğitimi alma durumuna da bağlanabilir.

Ekinci ve arkadaşları (2014) çalışmalarında aylık ortalama gelir seviyelerine göre "birey psikolojisi" ve "tesisler/ hizmet" alt boyutlarında anlamlı farklılıklar belirtmişlerdir. Lakot (2015) çalışmasında gelir durumuna göre anlamlı bir şekilde farklılaşma tespit ederken, Demirtaş ve İmamoğlu (2018) ise gelir durumuna göre anlamlı bir farklılık olmadığını belirlemişlerdir. Bu çalışmada da gelir seviyelerine göre boş zaman engellerinde anlamlı bir farkl111k tespit edilmemiştir $(\mathrm{p}>0,05)$. Farklılığın oluşmamasında, öğrencilerin gelir düzeylerinin birbirine yakın olmasının etkisi olabileceği düşünülmektedir.

Üniversite öğrencisi kadınlarda spor eğitimi almanın boş zaman engellerini etkilediği sonucuna varılmıştır. Sağlık durumunu iyi ve çok iyi olarak belirten kadın öğrencilerde boş zaman engelleri farklılık göstermemiştir. Sağlık durumu kötü veya iyi altında olan öğrencileri de kapsayan bir çalışmada boş zaman engellerinin araştırılması önerilir.

\section{Kaynakça}

Ağılönü, A. (2007). Yerel yönetimlerde rekreasyon hizmetleri ve model belirleme: Fethiye örneği. Yayınlanmamış doktora tezi, Marmara Üniversitesi Sağlık Bilimleri Enstitüsü.

Akatay, A. (2008). Örgütlerde Zaman Yönetimi. Selçuk Üniversitesi Sosyal Bilimler Dergisi, 10(1), 282-300.

Aksoy, Y. (2020). Rekreasyonel Faaliyet Olarak Fiziksel Aktivitelerin Otizmli Çocuklarda Sosyal İletişime Yönelik Etkileri, Gaziantep Üniversitesi Spor Bilimleri Dergisi, 5(1), 1-9. https://doi.org/10.31680/gaunjss.689747

Aksoy, Y. \& Arslan, O. (2019). Effects of Recreational Activity on Leisure Barriers between Students, Asian Journal of Education and Training, 5(4), 569-574. https://doi.org/10.20448/journal.522.2019.54.569.574 
Akyüz, H. \& Türkmen, M. (2016). Üniversite öğrencilerinin boş zaman faaliyetlerine yönelik tutumlarının incelenmesi: Bartın Üniversitesi örneği. International Journal of Science Culture and Sport, 1(4), 340-357. https://doi.org/10.14486/IntJSCS562

Alay, S. \& Koçak, S. (2003). Üniversite öğrencilerinin zaman yönetimleri ile akademik başarıları arasındaki ilişki. Kavram ve Uygulamada Eğitim Yönetimi Dergisi, 9(3), 326-335.

Alexandris, K., \& Carroll, B. (1997). Demographic differences in the perception of constraints on recreational sport participation: Results from a study in Greece. Leisure Studies, 16(2), 107125.

Arslan, S. (2013). Serbest Zaman-Rekreasyon ve Serbest Zaman Eğitimi (Yetişkin Eğitimi Baklş Açısılla). Nobel Yayıncılık.

Aslan, H., \& Imamoglu, O. (2020). Investigation of Leisure Strategies of Sports Educated Students. Asian Journal of Education and Training, 6(3), 468-473.

Atan, T., Tural, E., İmamoğlu, O., Çiçek, G. \& Tural, Ş. (2012). Physical activity levels of teachers and health professionals in Turkey. Health MED, 6(6), 1935-1942.

Baltaş, Z. \& Baltaş, A. (2012). Stres ve Başa Çıkma Yolları. Remzi Kitabevi.

Balc1, V., Demirtaş, M., Gürbüz, P., İlhan, A. \& Ersöz, V. (2003). Ankara'daki Üniversite Öğrencilerinin Boş Zaman Etkinliklerine Katılımlarının Araştırılması. Milli Eğitim Dergisi, $158,161-173$.

Batur, A. (2019). Türkiye'de atıcılık branşı ile ilgilenen sporcuların serbest zaman algisı ve engelleri. Yüksek lisans tezi, Batman Üniversitesi Sosyal Bilimler Enstitüsü.

Çimen, Z. \&Sarol, H. (2015). Serbest Zaman Tutumu: Üniversite öğrencilerine yönelik araştırma. III. Rekreasyon Araştırmaları Kongresi Bildiri Kitabı, 295-299.

Demirel, M. \&Harmandar, D. (2009). Üniversite Öğrencilerinin Rekreasyonel Etkinliklere Katılımlarında Engel Oluşturabilecek Faktörlerin Belirlenmesi. Uluslararası İnsan Bilimleri Dergisi, 6(1), 839-846.

Demirtaş, Ö. \& İmamoğlu, G. (2018). Spor ve Sanat Eğitimi Alan Üniversite Öğrencilerde Boş Zaman Engellerinin Araştırılması, Herkes İçin Spor ve Wellness Araştırmaları, (Editörler: M. Ali Öztürk, Süleyman Gönülateş). Akademisyen Kitabevi.

Dinç, H., Koca, H. B., Poyraz, A. \& Aydemir, K. (2019). Üniversite öğrencilerinin boş zaman anlamlarının incelenmesi. Türkiye Spor Bilimleri Dergisi, 3(1), 1-9. https://doi.org/10.32706/tusbid.479316

Ekinci, N. E., Kalkavan, A., Üstün, Ü.D. \& Gündüz, B. (2014). Üniversite Öğrencilerinin Sportif ve Sportif Olmayan Rekreatif Etkinliklere Katılmalarına Engel Olabilecek Unsurların İncelenmesi. Sportif Bakış: Spor ve Eğitim Bilimleri Dergisi, 1(1), 1-13.

Emir, E. (2012). Rekreatif Etkinliklere Katılımın Önündeki Engellerin Belirlenmesi: Üniversite Öğrencileri Örneği. Yüksek Lisans Tezi, Karadeniz Teknik Üniversitesi Eğitim Bilimleri Enstitüsü.

Ermiş, E., Akyol, P., Konca, E. \& İmamoğlu, O. (2019). Üniversite Öğrencilerinde Boş Zaman Engellerinin Cinsiyete ve Davranış Değişim Basamaklarına Göre Araştırılması. 3. Uluslararası Sosyal Bilimleri Kongresi, 154-155. (Tam Metin Bildiri/Sözlü Sunum), (Yayın No:5720743). 
Ermiş, E., Ermiş, A. \& İmamoğlu, O. (2018). Association Between Sport and Multiple Intelligences of Students in Adulthood Period. Turkish Studies Social Sciences, 13(18), 589598. http://dx.doi.org/10.7827/TurkishStudies.14093

Eryılmaz, G. \& Unur, K. (2019). Açık Alan Rekreasyon Etkinliklerine Katılan Bireylerin Pozitif ve Negatif Duygu Durumlarının Karşılaştırılması. Gastroia: Journal of Gastronomyand Travel Research, 3(4), (Özel Say1), 562-578.https://doi.org/10.32958/gastoria.577011

Goodman, F.R., Kashdan, T.B. \& İmamoğlu, A. (2020). Valuing Emotional Control in Social Anxiety Disorder: A Multimethod Study of Emotion Beliefs and Emotion Regulation. Emotion. Advance online publication. http://dx.doi.org/10.1037/emo0000750

Gülbahçe, Ö. (1996). Boş zamanları değerlendirme alışkanlıkları (Türkiye örneği). Yayınlanmamış yüksek lisans tezi, Atatürk Üniversitesi Sosyal Bilimler Enstitüsü.

Güler, H. (2017). Beden Eğitimi ve Spor Yüksekokullarında Öğrenim Gören Öğrencilerin Boş Zaman Engellerinin Boş Zaman Motivasyonlarına Etkisinin Araştırılması (Bartın Üniversitesi Örneği). Yüksek lisans tezi, Bartın Üniversitesi Eğitim Bilimleri Enstitüsü.

Güngörmüş, H.A., Yetim, A.A. \& Çalık, C. (2006). Ankara'daki Beden Eğitimi ve Spor Yüksekokullarında Görev Yapan Öğretim Elemanlarının Boş Zamanlarını Değerlendirme Biçimlerinin Araştırılması. Kastamonu Eğitim Dergisi, 14(1), 285-298.

Gürbüz, B. \& Karaküçük, S. (2007). Boş Zaman Engelleri Ölçeği-28: Ölçek Geliştirme, Geçerlik ve Güvenirlik Çalışması. Gazi Beden Eğitimi ve Spor Bilimleri Dergisi, 12(1), 3-10.

Gürbüz, B., Öncü, E. \& Emir, E. (2012). Boş zaman engelleri ölçeği: Yapı geçerliğinin test edilmesi, 12. Uluslararası Spor Bilimleri Kongresi, 12-14 Aralık, Denizli.

Hubbard, J. \& Mannell, R. C. (2001). Testing competing models of the leisure constraint negotiation process in a corporate employee recreation setting. Leisure Sciences, 23(3),145-163. https://doi.org/10.1080/014904001316896846

Karadeniz, F., Müftüler, M. \& Gülbeyaz, K. (2019). Üniversite Öğrencilerinin Serbest Zaman Aktivitelerine Yönelik Tutum ve Engellerinin İncelenmesi (Muğla Sitkı Koçman Üniversitesi Örneği). Spor ve Rekreasyon Araştırmaları Dergisi, 1(2), 21-36.

Karaküçük, S. (2008). Rekreasyon, boş zamanları değerlendirme (6. Baskl). Gazi Kitabevi.

Kirtepe, A. \& Uğurlu, F.M. (2018). Determination of the Leisure Time Management of Individuals Who GotoGym for Recreation Purposes, According to Distinctive Variables, TurkishStudies, 13(3), 783-792. http://dx.doi.org/10.7827/TurkishStudies.13146

Köse, N. \& Yılmaz, H. (2016). Leisure Time and Housewife: Nevşehir Example, International Periodical for the Languages, Literature and History of Turkish or Turkic, 11(21), 597-604. http://dx.doi.org/10.7827/TurkishStudies.9949

Lakot, K. (2015). Beden Ĕgitimi Öğretmeni Adaylarında Serbest Zaman Algisı ve Engelleri.Yüksek lisans tezi, Karadeniz Teknik Üniversitesi Eğitim Bilimleri Enstitüsü.

Lapa, T.Y. \& Köse, E. (2018). Serbest zaman engelleri ile engellerle baş etme stratejileri arasındaki iliş̧inin incelenmesi: Keşifsel bir çalışma. CBÜ Beden Eğitimi ve Spor Bilimleri Dergisi, 13(2), 356-375. https://doi.org/10.33459/cbubesbd.440506

Öztürk, F. \& Bayazıt, B. (2020). Halk Eğitim Merkezlerinde Çalışan Bireylerin Rekreatif Etkinliklere Katılımlarına Engel Olan Faktörlerin İncelenmesi (Kocaeli İli Örneği). Afyon Kocatepe Üniversitesi Sosyal Bilimler Dergisi, 22(1), 85-105. https://doi.org/10.32709/akusosbil.546415 
Öztürk, M.A. (2019). Üniversite Öğrencilerinin Rekreasyonel Fiziksel Aktivitelere Katılım Engellerinin Karş1laştırılması. Gelecek Vizyonlar Dergisi,3(1), 12-19. https://doi.org/10.29345/futvis.68

Solakumur, A., Özen, G., Yıldız, N. O. \& Ünlü, Y. (2019). Investigation of UniversityStudents' LeisureObstacles (Example of BartinProvince). Türkiye Spor Bilimleri Dergisi, 3(1), 33-41. https://doi.org/10.32706/tusbid.556262

Tolukan, E. (2010). Özel Yetenekle Illgili Bölümlerde Okuyan Üniversite Öğrencilerinin Rekreasyonel Aktivitelere Katılımlarına Engel Olabilecek Unsurların Belirlenmesi. Yüksek lisans tezi, Niğde Üniversitesi Sosyal Bilimler Enstitüsü.

Tordkilsen, G. (2005). LeisureandRecration Management (5. Baski). EveFNSpon. Tokyo. Melburne. Madras.

Turan, E.B., Gülşen, D.B.A. \& Bilaloğlu, M. (2019). Kadın çalışanların yaşam doyumu ile boş zaman engelleri arasındaki ilişsi: Akdeniz üniversitesi örneği. Gaziantep Üniversitesi Spor Bilimleri Dergisi, 4(1), 104-114. https://doi.org/10.31680/gaunjss.479340

Turgut, M., Akbulut, T., İmamoğlu, O. \& Çınar, V. (2018). The Effect of 3 Month Cardio Bosu Exercises on Some Motoric, Physical and Physiological Parameters in Sedentary Women, SpSocInt J PhEdSp, 18(2), 48-52.

Uzun, M., İmamoğlu, O., Yamaner, F., Deryahanoğlu, G. \& Yamaner, G. (2017). Rekreatif Etkinliklere Katılımı Engelleyen Faktörlerin İncelenmesi: Kız lisesi örneği. Journal of Human Sciences, 14(1), 950-962. https://doi.org/10.14687/jhs.v14i1.4174

Yalçın, İ. \& Ayhan, C. (2020). Sportif Rekreasyonel Etkinliklere Katılan Kadınlarda Fiziksel Görünüş Mükemmelliyetçiliği ve Psikolojik İyi Oluşun Öz Güven Üzerine Etkisi. SPORMETRE Beden Eğitimi ve Spor Bilimleri Dergisi, 18(1), 205-212. https://doi.org/10.33689/spormetre.625218 